\title{
Controversies in the Use of MIGS
}

\author{
Georges M. Durr, Paola Marolo, Antonio Fea, \\ and lqbal Ike K. Ahmed
}

\subsection{Introduction}

In this chapter, the discussion will focus on some of the "gray areas" that surround the use of minimally invasive glaucoma surgery (MIGS) in clinical practice. Many of the subjects covered review questions that physicians encounter when incorporating MIGS into their surgical practice. As a relative new-comer in the field of glaucoma surgery, these controversies highlight the challenges of implementing new technologies and future developments in an effervescent field of ophthalmology.

\subsection{Phaco Alone Versus Phaco/MIGS, Is It Worth It?}

Cataract surgery has a well-documented IOP-lowering effect [1-6]. Surgeons have often used this to their advantage in patients with glaucoma or ocular hypertension. With phacoemulsification (phaco) replacing extracapsular cataract surgery in the last two decades, the complication rates of cataract surgery have dramatically decreased, with excellent visual outcomes and rapid recovery. Currently, when a cataract is present in a glaucomatous eye, surgery may be offered in an attempt to

\footnotetext{
G. M. Durr ( $\square)$

Department of Ophthalmology, Université de Montréal, Montréal, QC, Canada

Department of Ophthalmology, Centre Hospitalier Universitaire de Montréal (CHUM), Montréal, QC, Canada
}

P. Marolo · A. Fea

Struttura Complessa Oculistica, Città della Salute e della Scienza di Torino, Dipartimento di Scienze Chirurgiche, Università degli Studi di Torino, Torino, Italy

\section{I. K. Ahmed}

Department of Ophthalmology and Vision Sciences, University of Toronto,

Toronto, ON, Canada 
reduce IOP and improve the visual acuity simultaneously. With the advent of MIGS, the surgeon now has a variety of potential methods to assist IOP-lowering at the time of cataract surgery. The question is: is there really an added benefit of phaco/ MIGS compared with phaco alone?

There have been numerous publications in the last few years, reporting the efficacy of MIGS in combination with cataract surgery, indicating an additional IOP lowering effect when compared with cataract surgery alone. In addition, there are a number of randomized clinical trials (RCT) addressing this issue [1-5]. On one hand, some large MIGS trials have shown that the additional IOP reduction conferred by MIGS is "only" 1.5-2.3 mmHg, with "only" 14-19.5\% less eyes achieving an IOP reduction $>20 \%$ compared with phaco alone $[1,3,5]$. Although the reported difference in IOP and success rate between phaco and phaco/MIGS seem small, these findings are still significant as they occur in the context of normal IOP, hence it is not as easy to show a difference between the two groups. Furthermore, proportional analyses of relevant clinical outcomes are important. For example, an increased proportion of patients in the MIGS groups compared to phaco alone remained medication-free at the end of the study period with differential rates varying between 13 and 35\% [1-3,5]. Some studies have shown that cataract surgery is more cost-effective when combined with MIGS than when performed alone [7], though more data are required to justify the additional MIGS procedure from an economic perspective. Another compelling argument is that phaco/MIGS results in fewer glaucoma surgical interventions later than with phaco alone. The HORIZON trial demonstrated that, at 3 years, a MIGS procedure could substantially reduce the requirement for later definitive glaucoma surgery in patients implanted with a Hydrus microstent $(0.6 \%)$ compared with those who had cataract surgery alone $(3.9 \%)[8]$.

It is difficult to account for surgical technique and verify accurate device placement in such trials. A well-targeted stent or a properly created trabeculotomy, which drains aqueous to a large aqueous vein (identified by looking at trypan blue outflow, increased trabecular pigmentation or blood reflux in the Schlemm's canal), is likely to enhance the IOP-lowering response [9]. A poor intra-operative view resulting in inappropriate device placement and a poor outcome can deter some surgeons. Better surgical training and more experience with different MIGS procedures are important in optimizing outcomes and maximizing the effect of MIGS implantation as an adjunct to cataract surgery.

The question remains as to whether this evidence of modest efficacy is truly clinically significant. From a patient's perspective, a reduction in drop load improves compliance, ocular surface irritation, and overall quality of life [10]. As poor compliance leads to glaucoma progression and increased costs to society, by implication adjunctive MIGS implantation should reduce both [11, 12]. At the time of cataract surgery, surgeons have a unique theoretical opportunity to improve a patients' quality of life and potentially delay progression or the requirement for future intervention. Above all, the high safety profile of MIGS gives surgeons more confidence in offering earlier surgery and this interventional mindset is now at the forefront of glaucoma therapy. 


\subsection{Trabecular Meshwork and Canal-Based Procedures: Cut Versus Stent Versus Dilate}

MIGS options have broadened in recent years. Many of these target Schlemm's canal, a small $36 \mathrm{~mm}$ circumferential conduit with an inner diameter of 300-400 $\mu \mathrm{m}$ [13]. Currently, there are three main approaches to increase aqueous outflow via this conventional outflow pathway: cutting (ostomies) (Kahook Dual Blade [KDB, New World Medical, Rancho Cucamonga, CA, USA]); Trabectome [NeoMedix Corporation, San Juan Capistrano, CA, USA]; gonioscopy-assisted transluminal trabeculotomy [GATT]) with a suture, iTrack [Ellex Medical Pty Ltd., Adelaide, Australia] or OMNI [Sight Sciences Inc., Menlo Park, CA, USA]; and excimer laser trabeculostomy [ELT, Excimer Laser AIDA, Glautec AG, Nürnberg, Germany]), dilation (viscocanalostomy with iTrack or OMNI) and stenting (iStent Trabecular Micro-Bypass Stent and iStent inject [Glaukos Corporation, San Clemente, CA, USA] and Hydrus Microstent [Ivantis Inc., Irvine, CA, USA]) (Table 10.1). All of these procedures aim to reduce the primary resistance to outflow, the trabecular meshwork (TM), through cutting or stenting to bypass the meshwork or dilating Schlemm's canal to reduce resistance to aqueous transiting the canal to enter the collector channels. Success with these procedures depends on the presence of a functional distal outflow system (beyond Schlemm's canal) and on whether the healing response subsequently obstructs aqueous flow to Schlemm's canal.

Cutting techniques either incise, excise, or ablate the TM. The opening size of the trabeculotomy required to obtain optimal IOP-lowering is still under debate. Some earlier studies looking at outflow resistance have shown that there was only a small additional decrease $(<10 \%)$ in outflow resistance with eyes receiving $360^{\circ}$ of trabeculotomy versus $120^{\circ}$ [14]. More studies are required to investigate the optimal trabeculotomy opening size required to achieve maximal efficacy in lowering IOP with the least amount of bleeding and postoperative hyphema. Upon review of current literature, hyphema occurs in approximately one-third of the eyes after GATT [15-17], $\sim 9 \%$ of eyes after Trabectome [18-20] and $~ 8 \%$ of eyes after KDB [21-23]. Bleeding rates seem to decrease as the opening size of the trabeculotomy decreases. With regard

Table 10.1 Breakdown of the different procedures separated by the mechanism of action

\begin{tabular}{l|l|l}
\hline Cut & Dilate & Stent \\
\hline $\begin{array}{l}\text { Kahook Dual Blade (New } \\
\text { World Medical, Rancho } \\
\text { Cucamonga, CA, USA) }\end{array}$ & $\begin{array}{l}\text { iTrack } \\
\text { Medical Pty Ltd., } \\
\text { Adelaide, Australia) }\end{array}$ & $\begin{array}{l}\text { iStent Trabecular Micro-Bypass Stent } \\
\text { and iStent inject (Glaukos Corporation, } \\
\text { San Clemente, CA, USA) }\end{array}$ \\
\hline $\begin{array}{l}\text { Trabectome } \\
\text { (NeoMedix Corporation, San } \\
\text { Juan Capistrano, CA, USA) }\end{array}$ & $\begin{array}{l}\text { OMNI }{ }^{\circledR} \text { (Sight } \\
\text { Sciences, Inc., } \\
\text { Menlo Park, CA, } \\
\text { USA) }\end{array}$ & $\begin{array}{l}\text { Hydrus Microstent (Ivantis, Inc., } \\
\text { Irvine, CA, USA) }\end{array}$ \\
\hline $\begin{array}{l}\text { Gonioscopy assisted } \\
\text { transluminal trabeculotomy }\end{array}$ & & \\
\hline $\begin{array}{l}\text { Excimer Laser Trabeculostomy } \\
\text { (Excimer Laser AIDA, Glautec } \\
\text { AG, Nürnberg, Germany) }\end{array}$ & & \\
\hline
\end{tabular}


to cutting procedures, data on whether goniotomy (only an incision through the TM, e.g., GATT) or goniectomy (cut AND excision of the TM, e.g., Trabectome and KDB) procedures differ in a long-term efficacy and complication rates are lacking.

Dilation of Schlemm's canal alone may reduce resistance to aqueous outflow from Schlemm's canal to the collector channels as well as providing a gentle stretch to the TM [24]. Studies have shown that herniation of the collector channels with the elevation of IOP leads to decreased outflow of aqueous humor [25]. Ab-interno canal viscodilation is a relatively new procedure, and although previous studies of ab-externo canaloplasty have shown good results, the surgery is more invasive and requires conjunctival and scleral dissection to access the canal [26].

Stenting allows aqueous to bypass the TM, the main area of outflow resistance, and directly flow into the Schlemm's canal with less trauma to the meshwork or angle than the cutting procedures. The two available options for stenting are the iStent (iStent Trabecular Micro-Bypass Stent and iStent inject) and the Hydrus Microstent. Both these implants bypass the TM, with the Hydrus Microstent being a longer implant, which also scaffolds Schlemm's canal. The iStent is the smallest device implantable in the human body and can be placed at multiple locations in the canal. Large randomized control trials have shown that these implants are associated with a very low risk of complications. Current evidence indicates that the iStent inject, the first-generation iStent Trabecular Micro-Bypass Stent and the Hydrus Microstent, confer moderate efficacy in lowering IOP, either as solo procedures or combined with phacoemulsification [27-30]. The advantage of stenting procedures over the cutting and dilating procedures is that it creates a permanent communication for aqueous to flow from the anterior chamber to the Schlemm's canal. These stents can be obstructed by iris or peripheral anterior synechiae (PAS) (1-2\%) [1$3]$, but elicit a much smaller inflammatory response than a cutting procedure and less blood reflux. Hence, theoretically, trabeculotomies are associated with a higher risk of PAS formation, hyphema, and membrane formation than stenting procedures.

Currently, there is no trial comparing the three approaches to Schlemm's canal. The choice of one trabecular bypass procedure over another depends on surgeon preference and expertise, cost, ease of access to the MIGS devices/procedures, and the relative risk of postoperative hyphema. Some may even consider combining stenting with dilation or dilation with ablation. The iTrack and OMNI devices allow a combination of canal dilation and TM ablation to be performed. Based on our clinical experience, it is likely that viscodilation of the canal decreases the incidence of postoperative hyphema by tamponading the reflux bleeding. Stenting, however, remains the least invasive trabecular bypass procedure with the lowest incidence of complications. Regardless of the surgery chosen, it is important that the surgeon is well-trained in the procedure, so as to achieve optimal efficacy with a low rate of complications.

\subsection{Endothelial Cell Loss and MIGS}

The COMPASS-XT trial (an extension of the COMPASS trial) uncovered a significant safety issue with the CyPass Micro-stent (Alcon Laboratories Inc., Fort Worth, Tx, USA) $[4,31]$. This led to Alcon's voluntary withdrawal of the device from the 
market due to concerns of a significant increase in endothelial cell loss (ECL) compared to patients who underwent cataract surgery alone after a 5-year follow-up. The only factor that correlated with ECL was the position of the device in the angle. The more retention rings that were visible on the CyPass Micro-Stent, the higher the likelihood of significant ECL [32]. Importantly, depending on the angle anatomy, a device with one ring visible can still be at risk of causing ECL if it remains in close proximity to the endothelium. This emphasizes the importance of correct device positioning, especially for suprachoroidal devices.

MIGS addresses a void in the conventional glaucoma treatment algorithm, which exists between topical drops/laser procedures and conventional glaucoma filtration surgery (trabeculectomy and tube implants). The high safety profile of MIGS is an important characteristic that allows it to be offered earlier in the glaucoma treatment algorithm, either in combination with cataract surgery or as a standalone procedure. The recent finding of increased ECL with the CyPass Micro-Stent led to a review of all the current MIGS procedures and their risk to the corneal endothelium. Fortunately, to date, no other MIGS device (iStent Trabecular Micro-Bypass Stent, iStent inject, Hydrus Microstent, Trabectome) is associated with an increase in ECL compared to cataract surgery alone (Table 10.2). In contrast, previous studies have reported ECL between 8.0 and $18.6 \%$ at 2 years for tube shunts and between 9.5 and $28.0 \%$ at 1 year and $9.9 \%$ at 2 years for trabeculectomy [33-41].

Much is still unknown with regard to MIGS and its effect on the corneal endothelium as well as the effect of cataract surgery and conventional glaucoma surgery on the cornea. Several factors, including device material, aqueous humor dynamics, and inflammatory mediators have been hypothesized to play a role in ECL after surgery. It is clear from the COMPASS-XT results that the further away the device is positioned from the endothelium, the lower the risk of ECL. Hence, the likely cause for ECL is mechanical trauma to the corneal endothelium by the device. Trabecular bypass MIGS devices (Hydrus Microstent and iStent) are located away from the corneal endothelium when correctly implanted in the angle, and early data show that they are not associated with an increase in ECL [42, 43]. Dilating or cutting procedures (GATT, OMNI, iTrack, KDB) are unlikely to increase ECL (apart from the initial trauma from the surgery) as they do not require a device to be permanently implanted in the eye, although this remains to be confirmed [44].

Subconjunctival MIGS devices such as the XEN Gel Implant (Allergan plc, Dublin, Ireland) and PRESERFLO MicroShunt (Santen Pharmaceutical Co. Ltd., Osaka, Japan) are bleb-forming procedures which are more effective in lowering IOP, hence are typically reserved for patients who need a greater reduction in intraocular pressure. The risk-benefit profile of patients who undergo subconjunctival MIGS device implantation differs from that of patients who undergo trabecular bypass or suprachoroidal MIGS device implantation. Similar to trabeculectomy and tube implants, subconjunctival MIGS devices are often used in the context of more advanced glaucoma, and hence, there is a higher tolerance and acceptance of potential complications in exchange for higher efficacy in lowering the IOP and preventing glaucoma progression. Only one study has examined ECL after implantation of the XEN Gel Implant and showed no significant change in endothelial cell count 
Table 10.2 Comparison of ECL rates between different MIGS procedures (adapted from reference [3])

\begin{tabular}{|c|c|c|c|c|}
\hline MIGS procedures & $N$ & $\begin{array}{l}\text { Follow-up } \\
\text { time }\end{array}$ & Mean \% ECL & $\begin{array}{l}\% \text { with } \\
\text { ECL }>30 \%\end{array}$ \\
\hline \multicolumn{5}{|l|}{ Schlemm Canal } \\
\hline \multirow[t]{2}{*}{$\begin{array}{l}\text { iStent inject } \\
\text { (Glaukos Corporation) }\end{array}$} & 505 & 24 months & $\begin{array}{l}13.1 \% \text { treatment } \\
12.3 \% \text { control }\end{array}$ & $\begin{array}{l}10.4 \% \text { treatment } \\
9.5 \% \text { control }\end{array}$ \\
\hline & $20^{\mathrm{a}}$ & 12 months & $13.2 \%$ & \\
\hline \multirow[t]{2}{*}{$\begin{array}{l}\text { Hydrus Microstent } \\
\text { (Ivantis, Inc.) }\end{array}$} & 556 & 24 months & $\begin{array}{l}14.0 \% \text { treatment } \\
10.0 \% \text { control }\end{array}$ & $\begin{array}{l}13.6 \% \text { treatment } \\
7.2 \% \text { control }\end{array}$ \\
\hline & & 36 months & $\begin{array}{l}15.0 \% \text { treatment } \\
11.0 \% \text { control }\end{array}$ & $\begin{array}{l}14.0 \% \text { treatment } \\
10.2 \% \text { control }\end{array}$ \\
\hline $\begin{array}{l}\text { Trabectome } \\
\text { (NeoMedix Corporation) }\end{array}$ & $80^{\mathrm{b}}$ & 12 months & No change & \\
\hline $\begin{array}{l}\text { Kahook Dual Blade } \\
\text { (New World Medical) }\end{array}$ & \multicolumn{4}{|c|}{ Unknown } \\
\hline $\begin{array}{l}\text { Ab-interno Canaloplasty } \\
\text { (Ellex Medical Pty Ltd) }\end{array}$ & \multicolumn{4}{|c|}{ Unknown } \\
\hline OMNI (Sight Sciences, Inc.) & \multicolumn{4}{|c|}{ Unknown } \\
\hline \multicolumn{5}{|l|}{ Supraciliary } \\
\hline $\begin{array}{l}\text { CyPass Micro-Stent } \\
\text { (Alcon Laboratories, Inc.) }\end{array}$ & 253 & 60 months & \begin{tabular}{|l|}
1 \\
$8.4 \%$ treatment \\
$7.5 \%$ control \\
\end{tabular} & $\begin{array}{l}27.2 \% \text { treatment } \\
10.0 \% \text { control }\end{array}$ \\
\hline $\begin{array}{l}\text { iStent Supra } \\
\text { (Glaukos Corporation) }\end{array}$ & \multicolumn{4}{|c|}{ Unknown } \\
\hline \multicolumn{5}{|l|}{ Subconjunctival } \\
\hline XEN Gel Implant (Allergan plc) & $11^{\mathrm{c}}$ & 12 months & No change $(+3.6 \%$ & \\
\hline $\begin{array}{l}\text { PRESERFLO MicroShunt } \\
\text { (Santen Pharmaceutical Co. } \\
\text { Ltd.) }\end{array}$ & \multicolumn{4}{|c|}{ Unknown } \\
\hline
\end{tabular}

$N=$ number of patients, $\mathrm{ECL}=$ endothelial cell loss, MIGS = microinvasive glaucoma surgery

aArriola-Villalobos et al. [43]

${ }^{b}$ Maeda et al. [44]

'Fea et al. [45]

after 1 year [45]. We hypothesize that the risk of progressive endothelial trauma is minimized by a properly positioned implant, which is parallel to the iris and enters the eye posteriorly to Schwalbe's line.

\subsection{Is the Suprachoroidal Space Dead?}

The supraciliary space has long been targeted with the aim of decreasing IOP and attempts to access suprachoroidal drainage date back to the 1930s with the use of horsehair to increase suprachoroidal aqueous outflow [46]. Several features of this space make it an alluring target for surgical therapy. Firstly, the uveoscleral pathway accounts for $20-54 \%$ of the aqueous humor outflow in a normal eye and this decreases with age, with the main restriction to aqueous flow arising from the ciliary muscle $[47,48]$. Secondly, there is a proven increase in uveoscleral outflow when 
drugs such as cholinergics and prostaglandin analogs are administered. Prostaglandin analogs are now the mainstay of topical glaucoma therapy due to their significant efficacy in reducing IOP $[47,48]$. Finally, traumatic cyclodialysis clefts may profoundly reduce IOP without bleb formation and this reduction can last for many years $[47,48]$. Unlike Schlemm's canal which is lined with endothelial cells, the suprachoroidal space is lined with myofibroblasts which predispose to fibrosis and scarring, hence the efficacy of suprachoroidal aqueous outflow in lowering IOP is more unpredictable. The advantages of draining aqueous to the suprachoroidal space include its size (indicating a large capacity for aqueous drainage) and, unlike the conventional aqueous outflow pathway, the reduction in IOP is not limited by the episcleral venous pressure.

These factors have resulted in the introduction of various implants and procedures to create and maintain a cyclodialysis cleft [49-53]. The disadvantages of previous suprachoroidal procedures or devices include high rates of intraoperative and postoperative bleeding, unpredictable efficacy in reducing IOP, hypotony, and sudden IOP spikes when the cleft closes. Biocompatible materials have been used to create a scaffold within the suprachoroidal space, creating a direct communication between the anterior chamber and the suprachoroidal space. The Gold Glaucoma Shunt (GGS, SOLX Ltd., Waltham, MA, USA) [54] and the STARflo Glaucoma Implant (iStar Medical, Isnes, Belgium) [55] are ab-externo suprachoroidal devices which require conjunctival as well as scleral dissection for implantation. Clinical data on the STARflo are limited, while the GGS has been associated with poor surgical outcomes [54]. Hence, the ab-externo approach to the suprachoroidal space has been abandoned for newer techniques utilizing an ab-interno approach. Until recently, there was only one commercially available ab-interno suprachoroidal MIGS device, the CyPass Micro-Stent (Alcon Laboratories Inc., Fort Worth, Tx, USA). The withdrawal of the CyPass Micro-Stent due to concerns of long-term ECL evident in the 5-year results of the COMPASS-XT trial has cast doubts on whether this space is a viable option after all $[56,57]$. However, the ECL associated with the CyPass Micro-Stent is likely due to the position of the device in the angle causing mechanical trauma to the corneal endothelium and does not appear to be a consequence of suprachoroidal aqueous drainage. Thus, it is important for suprachoroidal and other intraocular devices to be positioned away from the cornea, preferably parallel to the iris.

Compared to MIGS devices targeting the Schlemm's canal, suprachoroidal aqueous drainage can potentially reduce IOP to a dramatic extent as the resultant IOP is not limited by the episcleral venous pressure. Surgical implantation of suprachoroidal devices is also technically easier compared with the implantation of trabecular bypass devices. The disadvantages of suprachoroidal aqueous drainage include unpredictable efficacy in reducing IOP and postoperative fibrosis or scarring which can result in a sudden IOP spike. For refractory eyes which lack healthy and mobile conjunctiva, suprachoroidal aqueous drainage provides a viable alternative to further conjunctival filtration surgery [58]. In addition, suprachoroidal MIGS devices can be combined with devices or procedures which utilize other routes of aqueous drainage (conventional aqueous outflow pathway and subconjunctival drainage) to achieve better IOP control. 
The iStent Suprachoroidal Bypass System (iStent Supra, Glaukos Corporation, San Clemente, CA, USA) is another microstent that is in development with limited data available [59]. A further device currently under investigation, the MINIject ${ }^{\mathrm{TM}}$ (iStar Medical, Isnes, Belgium), is composed of a biocompatible silicone implant with micropores, the same material as the STARflo device. The advantage of this material lies in its ability to biointegrate in the suprachoroidal space. Currently, a randomized clinical trial (NCT03193736) is underway to evaluate the efficacy and safety of the MINIject, with clinical data reported at 6, 12, and 24 months. Preliminary results show a 39\% reduction in IOP with mean IOP of $14.2 \mathrm{mmHg}$ at 6 months, with $87.5 \%$ of patients being medication-free [60]. Although the suprachoroidal space is not well understood and much remains to be discovered about the optimization and maintenance of suprachoroidal aqueous drainage, current and new technologies on the horizon are promising.

\subsection{The Great Debate: Subconjunctival MIGS and Trabeculectomy}

Trabeculectomy is a time-tested glaucoma filtration surgery with multiple studies reporting long-term data substantiating its efficacy in reducing IOP by creating a filtering bleb [61-65]. However, this surgery is associated with a significant risk of complications and unpredictable results. Postoperative bleb management is complex, requiring many interventions (e.g., bleb needling and scleral flap suture removal) and visual rehabilitation can be prolonged. The success of trabeculectomy is highly dependent on surgical expertise as well as patient characteristics, with the creation of the scleral flap, suture tension, timing of suture-lysis, and conjunctival closure all having a significant impact on surgical outcomes. Furthermore, trabeculectomy is associated with a significant risk of complications, including hypotony, bleb leaks, and suprachoroidal hemorrhage. Ab-interno and ab-externo subconjunctival MIGS devices can potentially reduce the rate of complications, improve the predictability of surgical outcomes, and accelerate postoperative recovery. The efficacy of these procedures in reducing IOP has been a topic of debate in the glaucoma community and more prospective multicenter randomized trials are needed to compare the outcome of these devices with trabeculectomy.

The XEN Gel Implant is a 6-mm implant made of porcine gelatin cross-linked with glutaraldehyde, with an internal lumen diameter of $45 \mu \mathrm{m}$. It is implanted $a b$ interno through a clear corneal incision into the subconjunctival space to create a filtering bleb, bypassing the TM [66, 67]. The length and the inner lumen of the device confer $6-8 \mathrm{mmHg}$ of outflow resistance according to the Hagen-Poiseuille equation, hence protecting against hypotony. Despite the theoretical advantages of this approach, surgical outcomes can still be unpredictable. This is because microstents, which have a small lumen size, are at an increased risk of distal obstruction by tenon's capsule or fibrosis, or internal obstruction by pigment, heme, or fibrin. A large retrospective comparison of the XEN Gel Implant and trabeculectomy showed no difference in the failure rates and a similar safety profile between the two 
procedures [67]. In an attempt to position the implant consistently under the Tenon's capsule and to ensure that it is not occluded by the Tenon's, some surgeons prefer ab-externo implantation of the device with conjunctival peritomy or a transconjunctival approach to surgical implantation. Currently, no data are available comparing the different surgical approaches.

The PRESERFLO MicroShunt is a new subconjunctival MIGS device which is $8.5 \mathrm{~mm}$ long, with an internal lumen diameter of $70 \mu \mathrm{m}$. It is made of an inert biocompatible biomaterial called poly(styrene-block-isobutylene-block-styrene), or "SIBS" [68]. The MicroShunt requires conjunctival and Tenon's layer dissection to properly position the implant in the anterior chamber and under Tenon's. Early data from Batlle et al. show promising results in a small sample of patients [69].

Ab-externo XEN implantation and the surgical technique of the PRESERFLO MicroShunt both involve conjunctival peritomy to ensure optimal device placement under Tenon's capsule, but there are a few inherent differences between the two implants. The MicroShunt was designed to be implanted ab externo; hence, some features of the device are more adapted to that placement. Firstly, the fixation fins prevent migration of the device and limit peritubular flow. The XEN Gel Implant is injected through a needle, which creates a larger track allowing peritubular flow, resulting in a higher incidence of early postoperative hypotony. The MicroShunt lumen is larger than the XEN Gel Implant and it is a longer and stiffer device. As a longer segment of the MicroShunt is located in the anterior chamber compared with the XEN Gel Implant, it may be more likely to damage the corneal endothelium or be in contact with the iris. Both implants are made of non-inflammatory and biocompatible material (SIBS for the PRESERFLO MicroShunt and crosslinked porcine gelatin for the XEN Gel Implant).

Subconjunctival MIGS devices control aqueous outflow into the subconjunctival space to form a filtering bleb with potentially fewer complications and a more uneventful postoperative course. The efficacy of these novel devices is potentially comparable to trabeculectomy, with a lower risk of complications and more predictable outcomes. Whether these subconjunctival MIGS devices will eventually replace trabeculectomy or be used earlier in the glaucoma treatment paradigm remains to be seen.

\section{References}

1. Samuelson TW, Katz LJ, Wells JM, et al. Randomized evaluation of the trabecular microbypass stent with phacoemulsification in patients with glaucoma and cataract. Ophthalmology. 2011;118:459-67.

2. Pfeiffer N, Garcia Feijoo JG, Martinez JM, et al. A randomized trial of a Schlemm's canal microstent with phacoemulsification for reduction of intraocular pressure in open angle glaucoma. Ophthalmology. 2015;122:1283-93.

3. Samuelson TW, Chang DF, Marquis R, Flowers B, Lim KS, Ahmed IIK, Jampel HD, Aung T, Crandall AS, Singh K, HORIZON Investigators. A Schlemm Canal Microstent for intraocular pressure reduction in primary open-angle glaucoma and cataract: the HORIZON Study. Ophthalmology. 2019;126:29-37. 
4. Vold S, Ahmed II, Craven ER, et al. Two-year COMPASS trial results: supraciliary microstenting with phacoemulsification in patients with open-angle glaucoma and cataracts. Ophthalmology. 2016;123:2103-12.

5. Samuelson TW, Sarkisian SR Jr, Lubeck DM, Stiles MC, Duh YJ, Romo EA, Giamporcaro JE, Hornbeak DM, Katz LJ, iStent inject Study Group. Prospective, randomized, controlled pivotal trial of an ab interno implanted trabecular micro-bypass in primary open-angle glaucoma and cataract: two-year results. Ophthalmology. 2019;126(6):811-21.

6. Mansberger SL, Gordon MO, Jampel H, Bhorade A, Brandt JD, Wilson B, Kass MA, Ocular Hypertension Treatment Study Group. Reduction in intraocular pressure after cataract extraction: the Ocular Hypertension Treatment Study. Ophthalmology. 2012;119(9):1826-31.

7. Patel V, Ahmed I, Podbielski D, Falvey H, Murray J, Goeree R. Cost-effectiveness analysis of standalone trabecular micro-bypass stents in patients with mild-to-moderate open-angle glaucoma in Canada. J Med Econ. 2019;22(4):390-401.

8. Ivantis Announces Groundbreaking 3 Year Results from FDA Clinical Trial; First Device in Minimally Invasive Glaucoma Surgical (MIGS) Category to Demonstrate Significant Long Term Reduction of Severe Major Surgeries for Glaucoma Patients. https://www.prnewswire. com/news-releases/ivantis-announces-groundbreaking-3-year-results-from-fda-clinicaltrial-first-device-in-minimally-invasive-glaucoma-surgical-migs-category-to-demonstratesignificant-long-term-reduction-of-severe-major-surgeries-for-glaucoma-pa-300842527. html?tc=eml_cleartime

9. Huang AS, Saraswathy S, Dastiridou A, Begian A, Mohindroo C, Tan JC, Francis BA, Hinton DR, Weinreb RN. Aqueous angiography-mediated guidance of trabecular bypass improves angiographic outflow in human enucleated eyes. Invest Ophthalmol Vis Sci. 2016;57(11):4558-65.

10. Gazzard G, Konstantakopoulou E, Garway-Heath D, Garg A, Vickerstaff V, Hunter R, Ambler G, Bunce C, Wormald R, Nathwani N, Barton K, Rubin G, Buszewicz M, LiGHT Trial Study Group. Selective laser trabeculoplasty versus eye drops for first-line treatment of ocular hypertension and glaucoma (LiGHT): a multicentre randomised controlled trial. Lancet. 2019;393(10180):1505-16.

11. Traverso CE, Walt JG, Kelly SP, Hommer AH, Bron AM, Denis P, Nordmann JP, Renard JP, Bayer A, Grehn F, Pfeiffer N, Cedrone C, Gandolfi S, Orzalesi N, Nucci C, Rossetti L, AzuaraBlanco A, Bagnis A, Hitchings R, Salmon JF, Bricola G, Buchholz PM, Kotak SV, Katz LM, Siegartel LR, Doyle JJ. Direct costs of glaucoma and severity of the disease: a multinational long term study of resource utilisation in Europe. Br J Ophthalmol. 2005;89(10):1245-9.

12. Sleath B, Blalock S, Covert D, Stone JL, Skinner AC, Muir K, Robin AL. The relationship between glaucoma medication adherence, eye drop technique, and visual field defect severity. Ophthalmology. 2011;118(12):2398-402.

13. Zhou J, Smedley GT. A trabecular bypass flow hypothesis. J Glaucoma. 2005;14(1):74-83.

14. Rosenquist R, Epstein D, Melamed S, Johnson M, Grant WM. Outflow resistance of enucleated human eyes at two different perfusion pressures and different extents of trabeculotomy. Curr Eye Res. 1989;8(12):1233-40.

15. Grover DS, Smith O, Fellman RL, Godfrey DG, Gupta A, Montes de Oca I, Feuer WJ. Gonioscopy-assisted transluminal trabeculotomy: an ab interno circumferential trabeculotomy: 24 months follow-up. J Glaucoma. 2018;27(5):393-401.

16. Rahmatnejad K, Pruzan NL, Amanullah S, Shaukat BA, Resende AF, Waisbourd M, Zhan T, Moster MR. Surgical outcomes of Gonioscopy-assisted Transluminal Trabeculotomy (GATT) in patients with open-angle glaucoma. J Glaucoma. 2017;26(12):1137-43.

17. Baykara M, Poroy C, Erseven C. Surgical outcomes of combined gonioscopy-assisted transluminal trabeculotomy and cataract surgery. Indian J Ophthalmol. 2019;67(4):505-8.

18. Minckler D, Mosaed S, Dustin L, Brian Francis M, Trabectome Study Group. Trabectome (trabeculectomy-internal approach): additional experience and extended follow-up. Trans Am Ophthalmol Soc. 2008;106:149-59. discussion 159-60

19. Ting JL, Damji KF, Stiles MC, Trabectome Study Group. Ab interno trabeculectomy: outcomes in exfoliation versus primary open-angle glaucoma. J Cataract Refract Surg. 2012;38(2):315-23. 
20. Ahuja Y, Ma Khin Pyi S, Malihi M, Hodge DO, Sit AJ. Clinical results of ab interno trabeculotomy using the trabectome for open-angle glaucoma: the Mayo Clinic series in Rochester, Minnesota. Am J Ophthalmol. 2013;156(5):927-935.e2.

21. Dorairaj SK, Kahook MY, Williamson BK, Seibold LK, ElMallah MK, Singh IP. A multicenter retrospective comparison of goniotomy versus trabecular bypass device implantation in glaucoma patients undergoing cataract extraction. Clin Ophthalmol. 2018;12:791-7.

22. Berdahl JP, Gallardo MJ, ElMallah MK, Williamson BK, Kahook MY, Mahootchi A, Rappaport LA, Lazcano-Gomez GS, Díaz-Robles D, Dorairaj SK. Six-month outcomes of goniotomy performed with the Kahook dual blade as a stand-alone glaucoma procedure. Adv Ther. 2018;35(11):2093-102.

23. Salinas L, Chaudhary A, Berdahl JP, Lazcano-Gomez GS, Williamson BK, Dorairaj SK, Seibold LK, Smith S, Aref AA, Darlington JK, Jimenez-Roman J, Mahootchi A, Boucekine M, Mansouri K. Goniotomy using the Kahook dual blade in severe and refractory glaucoma: 6-month outcomes. J Glaucoma. 2018;27(10):849-55.

24. Gallardo MJ, Supnet RA, Ahmed IIK. Viscodilation of Schlemm's canal for the reduction of IOP via an ab-interno approach. Clin Ophthalmol. 2018;12:2149-55.

25. Battista SA, Lu Z, Hofmann S, Freddo TF, Overby DR, Gong H. Reduction of the available area for aqueous humor outflow and increase in meshwork herniations into collector channels following acute IOP elevation in bovine eyes. Invest Ophthalmol Vis Sci. 2008;49:5346-52.

26. Lewis RA, von Wolff K, Tetz M, Koerber N, Kearney JR, Shingleton BJ, Samuelson TW. Canaloplasty: three-year results of circumferential viscodilation and tensioning of Schlemm's canal using a microcatheter to treat open-angle glaucoma. J Cataract Refract Surg. 2011;37:682-90.

27. Ahmed IIK, Fea A, Au L, Ang RE, Harasymowycz P, Jampel H, Samuelson TW, Chang DF, Rhee DJ, COMPARE Investigators. A prospective randomized trial comparing Hydrus and iStent micro-invasive glaucoma glaucoma surgery implants for standalone treatment of openangle glaucoma: The COMPARE Study. Ophthalmology. 2019;S0161-6420:31710-X.

28. Katz LJ, Erb C, Carceller Guillamet A, Fea AM, Voskanyan L, Wells JM, Giamporcaro JE. Prospective, randomized study of one, two, or three trabecular bypass stents in openangle glaucoma subjects on topical hypotensive medication. Clin Ophthalmol. 2015;9:2313-20.

29. Fea AM, Belda JI, Rękas M, Jünemann A, Chang L, Pablo L, Voskanyan L, Katz LJ. Prospective unmasked randomized evaluation of the istent inject versus two ocular hypotensive agents in patients with primary open-angle glaucoma. Clin Ophthalmol. 2014;8:875-82.

30. Fea AM, Ahmed II, Lavia C, Mittica P, Consolandi G, Motolese I, Pignata G, Motolese E, Rolle T, Frezzotti P. Hydrus microstent compared to selective laser trabeculoplasty in primary open angle glaucoma: one year results. Clin Exp Ophthalmol. 2017;45:120-7.

31. Preliminary ASCRS CyPass withdrawal consensus statement. ASCRS. 2018. http://ascrs.org/ CyPass_Statement. Accessed 19 May 2019.

32. Durr G, Ahmed IIK. Endothelial cell loss and MIGS: what we know and don't know. Glaucoma Today. September/October 2018. http://glaucomatoday.com/2018/10/ endothelial-cell-loss-and-migs-what-we-know-and-dont-know/

33. Lee EK, Yun YJ, Lee JE, Yim JH, Kim CS. Changes in corneal endothelial cells after Ahmed glaucoma valve implantation: 2-year follow-up. Am J Ophthalmol. 2009;148(3):361-7.

34. Kim KN, Lee SB, Lee YH, Lee JJ, Lim HB, Kim CS. Changes in corneal endothelial cell density and the cumulative risk of corneal decompensation after Ahmed glaucoma valve implantation. Br J Ophthalmol. 2016;100(7):933-8.

35. Tan AN, Webers CA, Berendschot TT, et al. Corneal endothelial cell loss after Baerveldt glaucoma drainage device implantation in the anterior chamber. Acta Ophthalmol. 2017;95(1):91-6.

36. Tojo N, Hayashi A, Consolvo-Ueda T, Yanagisawa S. Baerveldt surgery outcomes: anterior chamber insertion versus vitreous cavity insertion. Graefes Arch Clin Exp Ophthalmol. 2018;6:2191-200. https://doi.org/10.1007/s00417-018-4116-4.

37. Arnavielle S, Lafontaine PO, Bidot S, Creuzot-Garcher C, D'Athis P, Bron AM. Corneal endothelial cell changes after trabeculectomy and deep sclerectomy. J Glaucoma. 2007;16(3):324-8.

38. Nassiri N, Nassiri N, Rahnavardi M, Rahmani L. A comparison of corneal endothelial cell changes after 1-site and 2-site phacotrabeculectomy. Cornea. 2008;27(8):889-94. 
39. Storr-Paulsen T, Norregaard JC, Ahmed S, Storr-Paulsen A. Corneal endothelial cell loss after mitomycin C-augmented trabeculectomy. J Glaucoma. 2008;17(8):654-7.

40. Konopińska J, Deniziak M, Saeed E, et al. Prospective randomized study comparing combined phaco-ExPress and phacotrabeculectomy in open angle glaucoma treatment: 12-month followup. J Ophthalmol. 2015;2015:720109.

41. Buys YM, Chipman ML, Zack B, Rootman DS, Slomovic AR, Trope GE. Prospective randomized comparison of one- versus two-site phacotrabeculectomy two-year results. Ophthalmology. 2008;115(7):1130-1133.e1.

42. Samuelson TW, Chang DF, Marquis R, HORIZON Investigators, et al. A Schlemm canal microstent for intraocular pressure reduction in primary open-angle glaucoma and cataract: the HORIZON study. Ophthalmology. 126:29-37. https://doi.org/10.1016/j.ophtha.2018.05.012.

43. Arriola-Villalobos P, Martínez-de-la-Casa JM, et al. Mid-term evaluation of the new Glaukos iStent with phacoemulsification in coexistent open-angle glaucoma or ocular hypertension and cataract. Br J Ophthalmol. 2013;97(10):1250-5.

44. Maeda M, Watanabe M, Ichikawa K. Evaluation of trabectome in open-angle glaucoma. J Glaucoma. 2013;22(3):205-8.

45. Fea AM, Spinetta R, Cannizzo PML, et al. Evaluation of bleb morphology and reduction in IOP and glaucoma medication following implantation of a novel gel stent. J Ophthalmol. 2017;2017:9364910.

46. Row H. Operation to control glaucoma. Arch Ophthalmol. 1935;12:325-9.

47. Alm A, Nilsson SF. Uveoscleral outflow—a review. Exp Eye Res. 2009;88(4):760-8.

48. Samples JR, Ahmed IIK. Surgical innovations in glaucoma. 1st ed. New York: Springer Science. p. 33-41.

49. Troncoso MU. Cyclodialysis with insertion of a metal implant in the treatment of glaucoma. Arch Ophthalmol. 1940;23:270-300.

50. Bick MW. Use of tantalum for ocular drainage. Arch Ophthalmol. 1949;42:375-88.

51. Bietti GB. The present state of the use of plastics in eye surgery. Acta Ophthalmol. 1955;33:337-70.

52. Klemm M, Balazs A, Draeger J, Wiezorrek R. Experimental use of space-retaining substances with extended duration: functional and morphological results. Graefes Arch Clin Exp Ophthalmol. 1995;233(9):592-7.

53. Jordan JF, Engels BF, Dinslage S, et al. A novel approach to suprachoroidal drainage for the surgical treatment of intractable glaucoma. J Glaucoma. 2006;15(3):200-5.

54. Melamed S, Ben Simon GJ, Goldenfeld M, Simon G. Efficacy and safety of gold micro shunt implantation to the supraciliary space in patients with glaucoma: a pilot study. Arch Ophthalmol. 2009;127(3):264-9.

55. Fili S, Wölfelschneider P, Kohlhaas M. The STARflo glaucoma implant: preliminary 12 months results. Graefes Arch Clin Exp Ophthalmol. 2018;256(4):773-81.

56. Potential eye damage from Alcon CyPass Micro-Stent used to treat open-angle glaucoma: FDA safety communication. FDA. September 14, 2018. www.fda.gov/MedicalDevices/Safety/ AlertsandNotices/ucm620646.htm.

57. Endothelial cell loss and MIGS: what we know and don't know. September-October 2018. http:// glaucomatoday.com/2018/10/endothelial-cell-loss-and-migs-what-we-know-and-dont-know/

58. Hopen ML, Patel S, Gallardo MJ. Cypass supraciliary stent in eye with chronic angle closure and postvitrectomy with silicone oil. J Glaucoma. 2018;27(10):e151-3.

59. Myers JS, Masood I, Hornbeak DM, Belda JI, Auffarth G, Jünemann A, Giamporcaro JE, Martinez-de-la-Casa JM, Ahmed IIK, Voskanyan L, Katz LJ. Prospective evaluation of two iStent $\left({ }^{\circledR}\right)$ trabecular stents, one iStent supra $\left({ }^{\circledR}\right)$ suprachoroidal stent, and postoperative prostaglandin in refractory glaucoma: 4-year outcomes. Adv Ther. 2018;35(3):395-407.

60. Denis P, Hirneiß C, Reddy KP, Kamarthy A, Calvo E, Hussain Z, Ahmed IIK. A first-in-human study of the efficacy and safety of MINIject in patients with medically uncontrolled openangle glaucoma (STAR-I). Ophthalmol Glaucoma. 2019;2:290-7. https://doi.org/10.1016/j. ogla.2019.06.001. 
61. Gedde SJ, Schiffman JC, Feuer WJ, Herndon LW, Brandt JD, Budenz DL. Treatment outcomes in the tube versus trabeculectomy (TVT) study after five years of follow-up. Am J Ophthalmol. 2012;153(5):789-803.e2. https://doi.org/10.1016/j.ajo.2011.10.026.

62. Matlach J, Dhillon C, Hain J, Schlunck G, Grehn F, Klink T. Trabeculectomy versus canaloplasty (TVC study) in the treatment of patients with open-angle glaucoma: a prospective randomized clinical trial. Acta Ophthalmol. 2015;93:753-61. https://doi.org/10.1111/aos.12722.

63. Gedde SJ, Chen PP, Heuer DK, et al. The primary tube versus trabeculectomy study. Ophthalmology. 2018;125(5):774-81. https://doi.org/10.1016/j.ophtha.2017.10.037.

64. Gedde SJ, Feuer WJ, Shi W, et al. Treatment outcomes in the primary tube versus trabeculectomy study after 1 year of follow-up. Ophthalmology. 2018;125(5):650-63. https://doi. org/10.1016/j.ophtha.2018.02.003.

65. Kirwan JF, Lockwood AJ, Shah P, et al. Trabeculectomy in the 21st century: a multicenter analysis. Ophthalmology. 2013;120:2532-9. https://doi.org/10.1016/j.ophtha.2013.07.049.

66. Reitsamer H, Sng C, Vera V, et al. Two-year results of a multicenter study of the ab interno gelatin implant in medically uncontrolled primary open-angle glaucoma. Graefes Arch Clin Exp Ophthalmol. 2019;257:983-96. https://doi.org/10.1007/s00417-019-04251-z.

67. Schlenker MB, Gulamhusein H, Conrad-Hengerer I, et al. Efficacy, safety, and risk factors for failure of standalone $\mathrm{Ab}$ Interno Gelatin microstent implantation versus standalone trabeculectomy. Ophthalmology. 2017;124:1579-88. https://doi.org/10.1016/j.ophtha.2017.05.004.

68. Pinchuk L, Wilson GJ, Barry JJ, Schoephoerster RT, Parel JM, Kennedy JP. Medical applications of poly(styrene-block-isobutylene-block-styrene) ("SIBS"). Biomaterials. 2008;29(60):448. https://doi.org/10.1016/j.biomaterials.2007.09.041.

69. Batlle JF, Fantes F, Riss I, et al. Three-year follow-up of a novel aqueous humor microshunt. J Glaucoma. 2016;25:e58-65. https://doi.org/10.1097/IJG.0000000000000368.

Open Access This chapter is licensed under the terms of the Creative Commons Attribution 4.0 International License (http://creativecommons.org/licenses/by/4.0/), which permits use, sharing, adaptation, distribution and reproduction in any medium or format, as long as you give appropriate credit to the original author(s) and the source, provide a link to the Creative Commons license and indicate if changes were made.

The images or other third party material in this chapter are included in the chapter's Creative Commons license, unless indicated otherwise in a credit line to the material. If material is not included in the chapter's Creative Commons license and your intended use is not permitted by statutory regulation or exceeds the permitted use, you will need to obtain permission directly from the copyright holder.

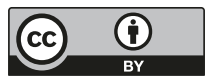

